\title{
Damage of hair follicle stem cells and alteration of keratin expression in external radiation-induced acute alopecia
}

\author{
NAOKI NANASHIMA, KOICHI ITO, TAKASHI ISHIKAWA, \\ MANABU NAKANO and TOSHIYA NAKAMURA
}

\begin{abstract}
Department of Biomedical Sciences, Division of Medical Life Sciences, Hirosaki University Graduate School of Health Sciences, Hirosaki, Japan
\end{abstract}

Received April 4, 2012; Accepted May 28, 2012

DOI: $10.3892 /$ ijmm.2012.1018

\begin{abstract}
Alopecia is known as a symptom of acute radiation, yet little is known concerning the mechanism of this phenomenon and the alteration of hair protein profiles. To examine this, 6-week-old male C57/BL6 mice were exposed to 6 Gy of X-ray irradiation, which caused acute alopecia. Their hair and skin were collected, and hair proteins were analyzed with liquid chromatography/electrospray-ionization mass spectrometry and immunohistochemistry. No change was observed in the composition of major hair keratins, such as Krt81, Krt83 and Krt86. However, cytokeratin Krt15 and CD34, which are known as hair follicle stem cell markers, were decreased in alopecic mice. Cytokeratin $\mathrm{Krt5}$, which is known as a marker for basal and undifferentiated keratinocytes, was increased in the epidermis of alopecic mice. These findings suggest that radiation damages hair stem cells and the differentiation of keratinocytes in the epidermis. For the evaluation of radiation exposure, chromosomal aberration is considered to be the gold standard, yet our results suggest that Krt5 may be a novel biological marker for acute radiation symptoms.
\end{abstract}

\section{Introduction}

At the time of the East Japan earthquake disaster of March 2011, a large quantity of radioactive material was scattered by the accident at the Fukushima Daiichi nuclear power plant, and workers and inhabitants were exposed to radiation (1-3). Acute radiation syndrome (ARS) is caused by exposure to a high dose of ionizing radiation within several months $(4,5)$. Generally, the effects of ARS such as gastrointestinal

Correspondence to: Dr Naoki Nanashima, Department of Biomedical Sciences, Division of Medical Life Sciences, Hirosaki University Graduate School of Health Sciences, 66-1 Hon-cho, Hirosaki, Japan

E-mail: nnaoki@cc.hirosaki-u.ac.jp

Key words: hair follicle stem cell, alopecia, cytokeratin, acute radiation syndrome disturbances and blood and bone marrow disorders are known to occur within several hours to several weeks after 1-6 Gy of radiation exposure $(4,6)$.

Hair loss is also an effect of ARS, but little is known about the mechanism underlying radiation-induced hair loss. In humans, hair loss is caused by radiation of more than $3 \mathrm{~Gy}$, and almost complete hair loss occurs within weeks of exposure to 6 Gy $(4,6)$. Since blood stem cells are sensitive to radiation (7), hair loss is thought to be caused by irradiationinduced stem cell damage, yet no studies have investigated this hypothesis. Additionally, as the skin and hair are the parts of the body most affected by radiation, skin and hair proteins may be biological markers for ARS.

Hair stem cells and many types of keratin protein are present in hair follicles (8-10). Keratin is an intermediate filament expressed region-specifically in epidermal cells, and many researchers have focused on cytokeratin as an epidermal cell differentiation marker. The large keratin multigene family comprises cytokeratins, which are differentially expressed in various types of epithelia, and hair keratins expressed in hard keratinized structures such as hairs, nails, and claws. These keratins can be divided into acidic type I and basic-to-neutral type II members, which form the 10 -nm intermediate filament network through the obligatory association of equimolar amounts of type I and type II keratins. Cytokeratins are known to assemble into strong networks that help attach keratinocytes together and anchor the epidermis to underlying layers of skin (11-13). Cytokeratins are also very useful as differentiation markers of cornified cells in the epidermis. Keratin (Krt)15 is a type I keratin, expressed in mouse bulge cells in the basal layer of the outer root sheath, and is known as a hair follicle stem cell marker (14-17). CD34 is expressed in a variety of stromal cells such as vascular endothelial, dermal dendritic and epithelial stem cells (14,18-20).

A basal layer of cells undergoes proliferation in the epithelial tissue of the skin, differentiates to form spinous cells and granule cells, and then cornifies and falls off. Stem cells remain throughout life in the basal layer as the ongoing source of epidermal renewal. Basal cells and spinous cells are well known to be highly susceptible to the effects of radiation, and cell division stops in cells affected by radiation (21).

$\mathrm{Krtl}$ is specifically expressed in the spinous layer of the epidermis along with Krt10, and Krt5 and Krt14 are expressed 
in undifferentiated keratinocytes and are downregulated during differentiation of the basal layer (22-24).

In this study, we investigated the mechanism of radiationinduced alopecia by focusing on alterations of these proteins in the hair and skin of irradiated mice, and we hypothesized that proteins such as keratins may be novel biological markers for ARS.

\section{Materials and methods}

Animals. Male C57/BL6 mice (Clea, Tokyo, Japan) 4 weeks of age, were housed in plastic cages in air-conditioned rooms with a $12 \mathrm{~h}$ light/dark cycle, and had free access to water and food. This study was carried out in accordance with the Guidelines for Animal Experimentation, Hirosaki University.

Exposure conditions. Five mice were irradiated with X-rays (150 kV, $20 \mathrm{~mA}$ ) using 0.5-mm aluminum and 0.3-mm copper filters at a distance of $45 \mathrm{~cm}$ from the focus at a dose of $6 \mathrm{~Gy}$ administered at a rate of $1.1 \mathrm{~Gy} / \mathrm{min}$ (MBR-1520R-3; X-ray generator; Hitachi Medical Corporation, Tokyo, Japan).

Histological analysis and immunohistochemistry. For wholemount examination, skin and hair were observed under a microscope (Biomedical Science, Tokyo, Japan). For histological examination, skin tissues were fixed in $10 \%$ formaldehyde and embedded in paraffin. Tissue sections $(4 \mu \mathrm{m})$ were passed through xylene and a graded alcohol series and stained with hematoxylin and eosin (H\&E). Immunohistochemical staining was performed with the Vectastain ABC-AP kit (Vector Laboratories, Inc., Burlingame, CA). The following primary antibodies were used: rabbit anti-Krt1 (1:500, v/v; Applied Biological Materials, Inc.), rabbit anti-Krt5 (1:500, v/v; Epitomics), rabbit anti-Krt10 (1:500, v/v; Assay Biotech), mouse anti-Krt15 (1:500, v/v; Santa Cruz Biotechnology, Inc.), and rat anti-CD34 (1:100, v/v; Abcam). Sections were then lightly counterstained with hematoxylin for microscopic examination. The specimens were examined and photographed using a fluorescence microscope (FSX100; Olympus, Tokyo, Japan).

SDS-polyacrylamide gel electrophoresis (PAGE) and western blotting. Hair and skin proteins were extracted from the hairs of mice, as described by Winter et al (25). Western blotting was performed according to the method of Towbin et al (26). In brief, extracted hair proteins were separated by SDS-PAGE (27) on $7.5 \%(\mathrm{w} / \mathrm{v})$ polyacrylamide gels and electroblotted to Hybond nitrocellulose membranes (GE Healthcare). Blots were probed with the primary antibody as described in 'Histological analysis and immunohistochemistry' followed by horseradish peroxidase-conjugated goat anti-rabbit IgG (1:2,000, v/v; GE Healthcare). Signals were detected with an ECL kit (GE Healthcare) according to the manufacturer's protocol.

Two-dimensional electrophoresis (2-DE). The hair proteins from alopecic mice were separated on a series of $7-\mathrm{cm}$ pH 5.0-8.0 immobilized $\mathrm{pH}$ gradient strips. The electrophoretic separation of protein was performed as described by O'Farrell (28). The 2-DE was carried out using Protean ${ }^{\circledR}$ IEF gels (Bio-Rad), according to the manufacturer's protocol. The gels were stained with Coomassie Brilliant Blue R-250.

To purify hair proteins, the gel portions containing each mouse hair protein resolved by $2-\mathrm{DE}$ were cut with a razor, homogenized in $1 \%$ SDS, $20 \mathrm{mM}$ Tris- $\mathrm{HCl}(\mathrm{pH} 8.0)$, and then rotated overnight. After centrifugation at $15,000 \mathrm{x} \mathrm{g}$ for $10 \mathrm{~min}$, the supernatant fractions were dialyzed against distilled water and then lyophilized.

Liquid chromatography/electrospray-ionization mass spectrometry (LC/ESI-MS). After being reduced with dithiothreitol and alkylated with iodoacetamide, proteins were dissolved in $100 \mathrm{mM} \mathrm{NH} \mathrm{HCO}_{3}$ containing $50 \mathrm{ng} / \mu 1$ trypsin and incubated at $37^{\circ} \mathrm{C}$ for $16 \mathrm{~h}$. The samples were applied to a Nano Frontier LC column, C18 (75 $\mu \mathrm{m}$ id x $150 \mathrm{~mm}$; Hitachi High-Tech, Tokyo, Japan) and eluted by a gradient flow of acetonitrile and distilled water containing $0.1 \%$ formic acid (flow rate $200 \mathrm{nl} / \mathrm{min}$ ). The eluted peptide fragments were analyzed using online coupled linear trap electrosprayionization mass spectrometry (Nano Frontier L; Hitachi High-Tech) at a heated capillary temperature of $140^{\circ} \mathrm{C}$, and voltage of $1.0 \mathrm{kV}$. Peptide sequence analysis was performed using BioLynx software (Micromass). The sequence information was submitted to the Mascot programs (http://www. matrixscience.com/), and Mascot scores $>34$ were considered to indicate the corresponding proteins.

TUNEL assay. Cell death was localized in tissue sections by TUNEL analysis (29). Paraffin tissue sections $(4-\mu \mathrm{m})$ were dewaxed at $60^{\circ} \mathrm{C}$ for $30 \mathrm{~min}$ and washed with toluene twice for $5 \mathrm{~min}$ each. Sections were hydrated through a graded series of ethanol and PBS and then incubated with proteinase $\mathrm{K}\left(20 \mu \mathrm{g} / \mathrm{ml}\right.$ in PBS) for $30 \mathrm{~min}$ at $37^{\circ} \mathrm{C}$. Thereafter, the ApopTag Plus Peroxidase in situ apoptosis detection kit (Intergen Discovery Products, Purchase, NY) was used for nick-end labeling according to the manufacturer's instructions. Fluorescein-linked nucleotides incorporated into DNA breaks were observed with a fluorescence microscope (FSX100; Olympus). Postweaning mammary tissue was included as a positive control.

\section{Results}

Whole mount and H\&E staining analysis. In X-ray irradiated mice, hair density decreased, and alopecia was induced after 5 weeks (Fig. 1A and B). Some hair became white, but inflammation was not observed in the skin (Fig. 1C and D).

SDS-PAGE and 2-DE analysis. To examine whether hair protein profiles differed between control mice and mice with radiation-induced alopecia, proteins extracted from hairs were subjected to SDS-PAGE and 2-DE. Protein staining with Coomassie Brilliant Blue revealed 2 major bands at $51 \mathrm{kDa}$ (basic hair keratin, $\mathrm{Hb}$ ) and $40 \mathrm{kDa}$ (acidic hair keratin, $\mathrm{Ha}$ ) in each mouse (Fig. 2A). The protein band pattern did not differ between control and alopecia hair. The hair protein spots from alopecic mice were shifted toward acidic $\mathrm{pH}$ (Fig. 2B) on 2-DE. This result suggested that irradiation changed the isoelectric point (PI) of proteins. To identify the proteins, gels were cut at 3 spots (X1-3) for the alopecia samples and 6 spots 


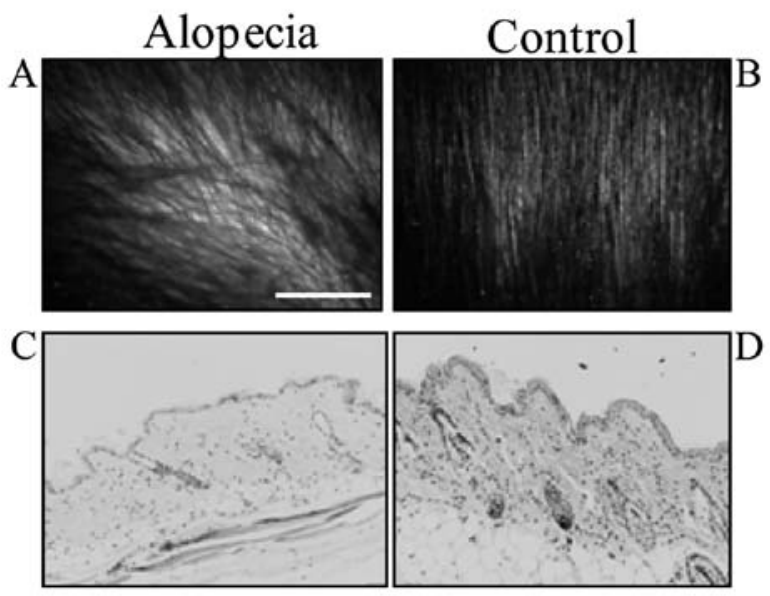

Figure 1. Whole-mount and histology analysis of the skin of alopecia and control mice 5 weeks after irradiation. Whole-mount skin of (A) alopecic and (B) control mice 5 weeks after irradiation with $6 \mathrm{~Gy}$. The skin from (C) alopecic and (D) control mice was fixed and stained with hematoxylin and eosin. (A) Scale bar, $3 \mathrm{~mm}$. (C and D) Original magnification, x100.

(C1-6) in the control mice, and subjected to LC/ESI-MS analysis (Fig. 2B).

Protein profiling by LC/ESI-MS analysis. The samples recovered from SDS gels were digested with trypsin, and their fragments were subjected to LC/ESI-MS analysis. This analysis revealed that most hair proteins were hair keratins (Table I) such as Krt86, Krt81, and Krt83 in the spots C1-3 and X1-2 from both groups (Fig. 2B). The composition of major hair keratins demonstrated no change, but the expression of Krt15, a marker of hair follicle stem cells, was detected in the control mice (Fig. 2B, spot C1) but not in the mice with alopecia. The absence of Krt15 expression in the alopecic mice, suggests that their hair stem cells were damaged. Krt10 was detected in $\mathrm{X} 1$, and $\mathrm{Krt1}$ and $\mathrm{Krt5b}$ were detected in the X2 spot (Fig. 2B) from the hair of alopecic mice (Table I). Since Krt1, Krt5 and Krt10 are known as epidermal markers, we focused on these cytokeratins in our immunohistochemical analysis. Furthermore, many additional proteins such as vimentin and tubulin were decreased in the hair of alopecic mice (Table I).

Immunohistochemistry. We next examined whether hair stem cells were damaged after irradiation using immunohistochemistry to detect CD34, a marker of hair follicle stem cells, as well as Krt15. With the anti-Krt15 antibody, the bulge and outer root sheath in the hair follicle of control mice showed a positive reaction, while the staining of hair follicles from irradiated mice was negative (Fig. 3A and B). Staining with the anti-CD34 antibody revealed a positive reaction in the peripheral layer of the outer root sheath (Fig. 3C and D). These positive cells were putative hair follicle stem cells. Krt1 and Krt10 were expressed in the spinous layer of epidermis, and levels did not differ between alopecic and control mice (Fig. 3E-H). Krt5 expression was clearly increased in the basal layer of alopecic mice (Fig. 3I and J). Krt5 consists of subtypes Krt5a and b, and the anti-Krt5 antibody used in this study detected both subtypes.
A
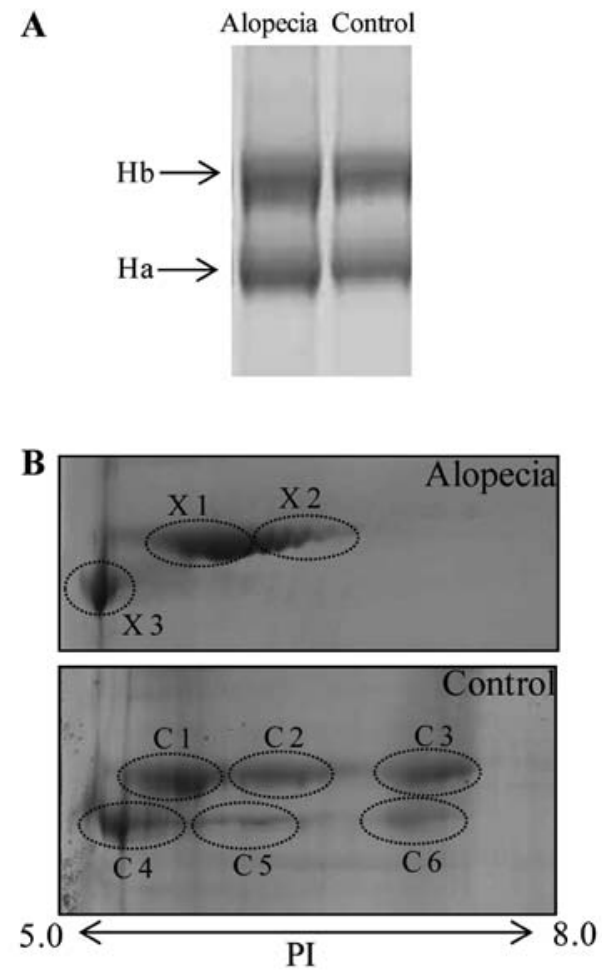

Figure 2. SDS-PAGE and 2-DE analysis of hair protein. (A) Hair proteins from alopecic and control mice resolved by SDS-PAGE. In each lane, $100 \mu \mathrm{g}$ protein was applied and stained with Coomassie Brilliant Blue. Hb, basic hair keratin; Ha, acidic hair keratin. (B) Two-dimensional electrophoresis was carried out using a Protean system. Protein staining with Coomassie Brilliant Blue revealed protein spots. X1-3 and C1-6 denote cut spots.

Western blot analysis. As expression of Kr5 was increased in alopecic mice using immunohistochemistry, to examine whether it could be used as a novel biomarker, we performed western blotting to analyze its expression. Krt5 was increased in alopecic mice, suggesting that it may be a useful novel biological marker for acute radiation symptoms (Fig. 4).

\section{Discussion}

Acute alopecia is a symptom of ARS, and although hair loss is thought to occur due to damage of hair follicle stem cells no previous study has investigated this hypothesis. In addition, no previous study has focused on the alteration of hair proteins such as keratins in radiation-induced alopecia. Therefore, we examined the mechanism of radiation-induced hair loss and profiling of hair proteins. When mice were irradiated with $6 \mathrm{~Gy}$, hair loss began after 5 weeks. As hair loss usually depends on apoptosis (30-32), we examined whether apoptotic cells were increased in alopecic mice by TUNEL assay. However, TUNEL-positive cells were not detected in alopecic mice, suggesting that alopecia was caused by necrosis of hair follicle stem cells in this study (data not shown).

To examine whether hair protein profiles differed between control and radiation-induced alopecic mice, hair proteins were extracted and subjected to SDS-PAGE and 2-DE for analysis of molecular mass and PI. Although the molecular mass did not differ, the hair protein spots from the alopecic mice were shifted toward an acidic pH (Fig. 2B). This result 
Table I. Identification of hair-derived proteins by LC/ESI-MS.

\begin{tabular}{|c|c|c|}
\hline Protein & Gene & Score \\
\hline \multicolumn{3}{|l|}{ Alopecia } \\
\hline a'Keratin, type II cuticular Hb6 & Krt86 & $3580^{\mathrm{a}}$ \\
\hline${ }^{\mathrm{a} K e r a t i n}$, type II cuticular $\mathrm{Hb} 3$ & $K r t 83$ & 3316 \\
\hline${ }^{\mathrm{a}}$ Keratin, type II cuticular $\mathrm{Hb} 1$ & Krt81 & 2770 \\
\hline a'Keratin, type II cuticular Hb5 & Krt85 & 2481 \\
\hline a'Keratin, type I cuticular Ha3-I & $K r t 33 a$ & 1892 \\
\hline aKeratin, type I cuticular $\mathrm{Ha} 4$ & Krt34 & 1687 \\
\hline aKeratin, type I cuticular Ha1 & Krt31 & 1631 \\
\hline${ }^{a}$ Keratin, type I cuticular Ha3-II & $K r t 33 b$ & 1625 \\
\hline Keratin, type I cuticular Ha5 & Krt35 & 236 \\
\hline Vimentin & $\operatorname{Vim}$ & 196 \\
\hline Keratin, type II cytoskeletal 5 & Krt5b & 141 \\
\hline Keratin, type II cytoskeletal 1 & Krt1 & 116 \\
\hline Keratin, type I cytoskeletal 10 & Krt10 & 108 \\
\hline Keratin, type II cytoskeletal 1b & $\operatorname{Krt77}$ & 65 \\
\hline Keratin, type I cytoskeletal 14 & Krt14 & 65 \\
\hline Tubulin $\alpha-1 \mathrm{~B}$ chain & Tubalb & 63 \\
\hline Keratin, type II cytoskeletal 6B & $K r t 6 b$ & 54 \\
\hline Keratin, type II cytoskeletal 5 & $K r t 5 a$ & 48 \\
\hline Keratin, type II cytoskeletal 79 & $K r t 79$ & 40 \\
\hline
\end{tabular}

\section{Control}

${ }^{a}$ Keratin, type II cuticular Hb6

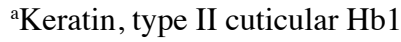

${ }^{\mathrm{a}}$ Keratin, type II cuticular $\mathrm{Hb} 3$

${ }^{a}$ Keratin, type I cuticular Ha3-I

${ }^{a}$ Keratin, type I cuticular $\mathrm{Ha} 4$

${ }^{a}$ Keratin, type I cuticular Ha1

${ }^{a}$ Keratin, type I cuticular Ha3-II

${ }^{a}$ Keratin, type II cuticular $\mathrm{Hb} 5$

Actin, cytoplasmic 1

Tubulin $\alpha-1 \mathrm{~B}$ chain

\begin{tabular}{lr} 
Krt86 & 4894 \\
Krt81 & 4709 \\
Krt83 & 4620 \\
Krt33a & 3449 \\
Krt34 & 3404 \\
Krt31 & 3360 \\
Krt33b & 3144 \\
Krt85 & 2964 \\
Actb & 979 \\
Tubalb & 502 \\
Tubb5 & 400 \\
Krt35 & 384 \\
Vim & 374 \\
Krt75 & 309 \\
Eefla1 & 205 \\
Eno1 & 193 \\
Krt15 & 129 \\
Krt79 & 91 \\
Krt17 & 86 \\
Aldoa & 83 \\
Krt72 & 78 \\
Pgk1 & 76 \\
Hnrnpk & 67 \\
Krt8 & 57 \\
Capn12 & 57 \\
Pkm2 & 54 \\
& \\
\hline
\end{tabular}

Table I. Continued.

\begin{tabular}{llc}
\hline Protein & Gene & Score \\
\hline Aldehyde dehydrogenase, cytosolic 1 & Aldhla7 & 51 \\
Glycine tyrosine-rich hair keratin protein & Krtap6-1 & 50 \\
Keratin, type II cytoskeletal 71 & Krt71 & 43 \\
Protein disulfide-isomerase & P4hb & 41 \\
\hline a'Hair keratin. Bold text indicates the keratins that were detected in only \\
alopecia or control mice.
\end{tabular}
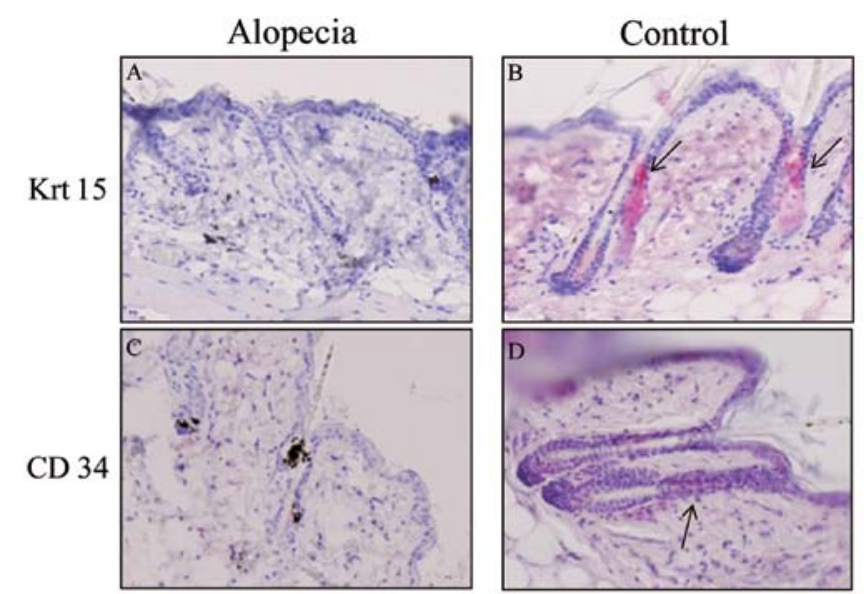

Krt 1
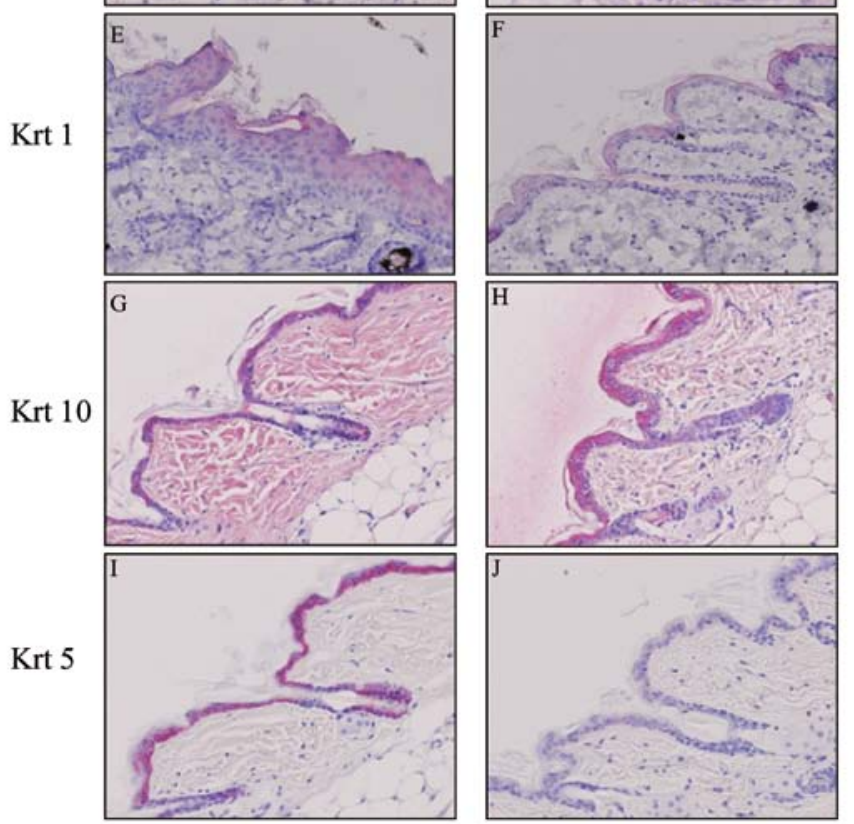

Figure 3. Immunohistochemical staining of skin. Skin sections of (A, C, E, $\mathrm{G}$ and $\mathrm{I}$ ) alopecic and (B, D, F, H and $\mathrm{J}$ ) control mice were stained with (A and B) anti-Krt15, (C and D) anti-CD34, (E and F) anti-Krt1, (G and H) anti$\mathrm{Krt5}$ and (I and $\mathrm{J}$ ) anti-Krt10. The arrows in B and D indicate Krt15- and CD34-positive cells, respectively. Original magnification, x200.

suggested that irradiation altered the PI of the proteins. Protein modifications such as phosphorylation or glycosylation are known to alter PI (33). To examine whether phosphorylation of these protein was modified by radiation, 


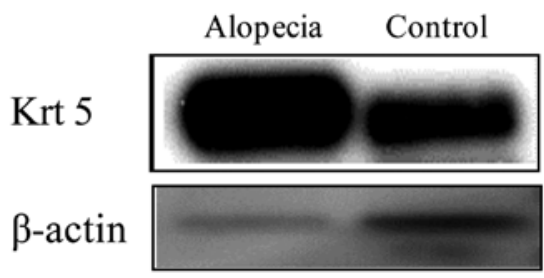

Figure 4. Western blot analysis of hair proteins. Hair proteins of alopecic and control mice were resolved by SDS-PAGE and then blotted with anti$\mathrm{Krt5}$ as described in Materials and methods. Each lane contains $100 \mu \mathrm{g}$ protein. $\beta$-actin was used as a control.

western blotting was performed with anti-phosphotyrosine and anti-phosphoserine antibodies. However, phosphorylation was not detected in hair proteins from the control or irradiated mice, suggesting that these proteins undergo another modification (data not shown).

With regard to LC/ESI-MS analysis and immunohistochemical staining, Krt15 and CD34 were decreased in the hair follicles of irradiated mice but not in the control mice (Table I and Fig. 3). These results suggest that damaged hair follicle stem cells could not differentiate normally, leading to hair loss in mice. Since vimentin is a mesenchymal cell marker, similar to CD34, our findings suggested damage to mesenchymal cells in alopecic mice (Table I). The hair keratin score did not change. As hair keratin is differentiated dead material, it may be less affected by radiation. Cytokeratins such as Krt5 were increased in hair protein from irradiated mice (Table I and Fig. 4). Since expression of Krt5 increases in the basal layer of the epidermis, keratinocytes may lose differentiation potential as a result of X-ray irradiation in alopecic mice.

Furthermore, after irradiation with a radioactivity dose of $6 \mathrm{~Gy}$, hair loss occurred, but expression of cytokeratins such as Krt1 and Krt10 increased as determined by LC/ESI-MS analysis. However, we could not detect differences between alopecic mice and control mice by immunohistochemistry. LC/ESI-MS analysis is a much more sensitive method compared to immunohistochemistry or western blotting, and therefore LC/ESI-MS analysis may have been able to reveal the increase in Krt1 and Krt10 in alopecic mice. This result suggested that Krt1 and Krt10 are not suitable for use as biological markers for acute radiation symptoms.

Tubulin is known to form microtubules and the centrosome and is an important protein in the differentiation of cells including keratinocytes (34). Both $\alpha$ and $\beta$-tubulin decreased in alopecic mice (Table I), suggesting that cell proliferation of keratinocyte was decreased in alopecic mice. These proteins may be associated with alopecia, but the details of this possible association remain to be clarified.

For the evaluation of radiation exposure, chromosomal aberration is considered the gold standard, yet this method requires technical expertise. There is a method to measure free radical production in biological tissues such as teeth and hair, in order to estimate the radiation exposure dose $(35,36)$. Electron spin resonance (ESR) is used to measure free radicals, and this method has been tested in hair (35). However, while the ESR method has been reported as an irradiation evaluation method using hair for biological dosim- etry, no previous reports have analyzed hair proteins by proteomics. The findings of this study suggest that Krt5 is a novel biological marker of ARS. Further studies are needed to examine whether expression of Krt5 is altered by differences in the period after irradiation, by the dose of radioactivity, and due to differences in skin organization between the mouse and human.

\section{Acknowledgements}

This study was supported in part by grants-in-aid for scientific research from the Ministry of Education, Culture, Sports, Science and Technology of Japan (nos. 20770096 and 22770119) and a Hirosaki University Grant for the Exploratory Research by Young Scientists.

\section{References}

1. Hirose K: 2011 Fukushima Dai-ichi nuclear power plant accident: summary of regional radioactive deposition monitoring results. J Environ Radioact: Nov 26, 2011 (Epub ahead of print).

2. Monzen S, Hosoda M, Tokonami S, et al: Individual radiation exposure dose due to support activities at safe shelters in Fukushima prefecture. PLoS One 6: e27761, 2011.

3. Tanimoto T, Uchida N, Kodama Y, Teshima T and Taniguchi S: Safety of workers at the Fukushima Daiichi nuclear power plant. Lancet 377: 1489-1490, 2011.

4. Donnelly EH, Nemhauser JB, Smith JM, et al: Acute radiation syndrome: assessment and management. South Med J 103: $541-546,2010$

5. Xiao M and Whitnall MH: Pharmacological countermeasures for the acute radiation syndrome. Curr Mol Pharmacol 2: 122-133, 2009

6. Stram DO and Mizuno S: Analysis of the DS86 atomic bomb radiation dosimetry methods using data on severe epilation. Radiat Res 117: 93-113, 1989.

7. Mauch P, Constine L, Greenberger J, et al: Hematopoietic stem cell compartment: acute and late effects of radiation therapy and chemotherapy. Int J Radiat Oncol Biol Phys 31: 1319-1339, 1995.

8. Langbein L, Rogers MA, Winter H, Praetzel S and Schweizer J: The catalog of human hair keratins. II. Expression of the six type II members in the hair follicle and the combined catalog of human type I and II keratins. J Biol Chem 276: 35123-35132, 2001.

9. Langbein L and Schweizer J: Keratins of the human hair follicle. Int Rev Cytol 243: 1-78, 2005.

10. Schweizer J, Langbein L, Rogers MA and Winter H: Hair follicle-specific keratins and their diseases. Exp Cell Res 313: 2010-2020, 2007.

11. Fuchs E: The cytoskeleton and disease: genetic disorders of intermediate filaments. Annu Rev Genet 30: 197-231, 1996.

12. Hatzfeld M and Weber K: The coiled coil of in vitro assembled keratin filaments is a heterodimer of type I and II keratins: use of site-specific mutagenesis and recombinant protein expression. J Cell Biol 110: 1199-1210, 1990.

13. Steinert PM, Marekov LN, Fraser RD and Parry DA: Keratin intermediate filament structure. Crosslinking studies yield quantitative information on molecular dimensions and mechanism of assembly. J Mol Biol 230: 436-452, 1993.

14. Cotsarelis G: Epithelial stem cells: a folliculocentric view. J Invest Dermatol 126: 1459-1468, 2006.

15. Jih DM, Lyle S, Elenitsas R, Elder DE and Cotsarelis G: Cytokeratin 15 expression in trichoepitheliomas and a subset of basal cell carcinomas suggests they originate from hair follicle stem cells. J Cutan Pathol 26: 113-118, 1999.

16. Liu Y, Lyle S, Yang Z and Cotsarelis G: Keratin 15 promoter targets putative epithelial stem cells in the hair follicle bulge. J Invest Dermatol 121: 963-968, 2003.

17. Tiede S, Bohm K, Meier N, Funk W and Paus R: Endocrine controls of primary adult human stem cell biology: thyroid hormones stimulate keratin 15 expression, apoptosis, and differentiation in human hair follicle epithelial stem cells in situ and in vitro. Eur J Cell Biol 89: 769-777, 2010. 
18. Hsu YC, Pasolli HA and Fuchs E: Dynamics between stem cells, niche, and progeny in the hair follicle. Cell 144: 92-105, 2011.

19. Nickoloff BJ: The human progenitor cell antigen (CD34) is localized on endothelial cells, dermal dendritic cells, and perifollicular cells in formalin-fixed normal skin, and on proliferating endothelial cells and stromal spindle-shaped cells in Kaposi's sarcoma. Arch Dermatol 127: 523-529, 1991.

20. Poblet E, Jimenez F, Godinez JM, Pascual-Martin A and Izeta A: The immunohistochemical expression of CD34 in human hair follicles: a comparative study with the bulge marker CK15. Clin Exp Dermatol 31: 807-812, 2006.

21. Fukuda H: Radiation-induced skin injuries. Kaku Igaku 40: 213-219, 2003 (In Japanese).

22. Alam H, Sehgal L, Kundu ST, Dalal SN and Vaidya MM: Novel function of keratins 5 and 14 in proliferation and differentiation of stratified epithelial cells. Mol Biol Cell 22: 4068-4078, 2011.

23. Fuchs $\mathrm{E}$ and Green $\mathrm{H}$ : Changes in keratin gene expression during terminal differentiation of the keratinocyte. Cell 19: 1033-1042, 1980.

24. Moll R, Divo M and Langbein L: The human keratins: biology and pathology. Histochem Cell Biol 129: 705-733, 2008.

25. Winter H, Hofmann I, Langbein L, Rogers MA and Schweizer J: A splice site mutation in the gene of the human type I hair keratin hHa1 results in the expression of a tailless keratin isoform. J Biol Chem 272: 32345-32352, 1997.

26. Towbin H, Staehelin T and Gordon J: Electrophoretic transfer of proteins from polyacrylamide gels to nitrocellulose sheets: procedure and some applications. Proc Natl Acad Sci USA 76: 4350-4354, 1979

27. Laemmli UK: Cleavage of structural proteins during the assembly of the head of bacteriophage T4. Nature 227: 680-685, 1970.
28. O'Farrell PH: High resolution two-dimensional electrophoresis of proteins. J Biol Chem 250: 4007-4021, 1975.

29. Waddell BJ, Hisheh S, Dharmarajan AM and Burton PJ Apoptosis in rat placenta is zone-dependent and stimulated by glucocorticoids. Biol Reprod 63: 1913-1917, 2000.

30. Harries MJ, Meyer KC and Paus R: Hair loss as a result of cutaneous autoimmunity: frontiers in the immunopathogenesis of primary cicatricial alopecia. Autoimmun Rev 8: 478-483, 2009.

31. Hendrix S, Handjiski B, Peters EM and Paus R: A guide to assessing damage response pathways of the hair follicle: lessons from cyclophosphamide-induced alopecia in mice. J Invest Dermatol 125: 42-51, 2005

32. Nakayama F, Hagiwara A, Kimura M, Akashi M and Imamura T: Evaluation of radiation-induced hair follicle apoptosis in mice and the preventive effects of fibroblast growth factor-1. Exp Dermatol 18: 889-892, 2009.

33. Larsen MR and Roepstorff P: Mass spectrometric identification of proteins and characterization of their post-translational modifications in proteome analysis. Fresenius J Anal Chem 366: 677-690, 2000

34. Roh JY, Kee SH, Choi JW, Lee JH, Lee ES and Kim YS: Expression of class II beta-tubulin in non-melanoma cutaneous tumors. J Cutan Pathol 34: 166-173, 2007.

35. Nakajima T: The use of organic substances as emergency dosimeters. Int J Appl Radiat Isot 33: 1077-1084, 1982.

36. Romanyukha AA and Regulla DF: Aspects of retrospective ESR dosimetry. Appl Radiat Isot 47: 1293-1297, 1996. 